\title{
ENRIQUE DUSSEL E PAULO FREIRE: REFLEXÕES SOBRE O OUTRO NA PEDAGOGIA LATINO-AMERICANA
}

Jenerton Arlan Schütz ${ }^{1}$

Ivan Luís Schwengber ${ }^{2}$

\begin{abstract}
RESUMO: O texto trata do problema clássico na Filosofia da Educação, a saber, sobre a presença do Outro na sala de aula. A partir das obras de Enrique Dussel e Paulo Freire, assumindo um fundo hermenêutico de análise, busca-se compreender o Outro como alguém introduzido no padrão cultural de inferioridade, na esteira da história colonial da América Latina. Consideramos que em um mundo globalizado, competitivo e excludente, parece não fazer mais sentido falar em Outro, não há uma bandeira pedagógica para ser defendida, parece não ser mais possível falar em opressor/oprimido, em pobre/rico, em colonizador e colonizado. Nesse sentido, propõe-se a possibilidade de pensar uma educação libertadora latino-americana, no intuito de buscar compreender e enaltecer a importância da experiência inicial do Outro na educação escolar, um outro que necessita ser ouvido, compreendido e incluído em um mundo humano comum.
\end{abstract}

Palavras-chave: Filosofia da Educação; Alteridade; Pedagogia latino-americana.

\section{ENRIQUE DUSSEL AND PAULO FREIRE: REFLECTIONS ON THE OTHER IN LATIN AMERICAN PEDAGOGY}

\begin{abstract}
The text deals with the classic problem in the Philosophy of Education, namely, about the presence of the Other in the classroom. From the works of Enrique Dussel and Paulo Freire, assuming a hermeneutical background of analysis, we seek to understand the Other as someone introduced into the cultural pattern of inferiority, in the wake of colonial history in Latin America. We consider that in a globalized, competitive and excluding world, it seems to make no sense to speak in Other, there is no pedagogical flag to be defended, it seems no longer possible to speak of oppressor / oppressed, poor / rich, colonized and colonized. In this sense, it is proposed the possibility of thinking about a liberating Latin American education, in order to seek to understand and extol the importance of the initial experience of the Other in school education, an Other that needs to be heard, understood and included in a common human world.
\end{abstract}

Keywords: Philosophy of Education; otherness; latin american pedagogy.

\section{INTRODUÇÃO}

\footnotetext{
1 Doutorando em Educação nas Ciências (Unijuí). Professor de História no Município de Santo Ângelo/RS. Contato: jenerton.xitz@ hotmail.com

${ }^{2}$ Mestre em Educação (Unochapecó), Especialista em Metodologia de Ensino de Filosofia (Educon) e Sociologia e Gestão Escolar (Uniasselvi), Licenciado em Filosofia (Fafimc). Professor da Rede Estadual de Ensino do Estado de Santa Catarina. Contato: ivan.s@unochapeco.edu.br
}

Programas de Pós-Graduação em Ciências Sociais e Filosofia - UNIOESTE - Rua da

Faculdade 645. Toledo - PR. CEP 85.903-000 Email: revistaalamedas@gmail.com 
A educação escolar tem sido, constantemente, alvo de discussões sobre o que ensinar, como ensinar, para que ensinar e qual o currículo mais conveniente para os estudantes em seus diversos contextos sociais. De um lado, reúnem-se desejos de uma educação voltada para a preparação da entrada no Ensino Superior, de outro, a preocupação de que a formação esteja voltada para o mercado de trabalho - formação de mão de obra. Estas e outras discussões podem ser consideradas legítimas e necessárias para a constituição de uma Educação de qualidade e preocupada com a formação integral dos sujeitos, entretanto, há um fenômeno de fundo intrigante, a saber, desta vez, ao menos na sociedade brasileira, os pesquisadores em educação foram, praticamente, desprezados e não ouvidos no que se refere às reformas educacionais ${ }^{3}$. A consulta fora feita, quase que exclusivamente, junto a grandes corporações e institutos que pretendem ter resultados com a educação ${ }^{4}$. Ademais, esta multifacetada visão sobre o papel da educação formal tem,como aspecto positivo, a possibilidade de ter chamado a atenção da opinião pública sobre o seu papel e a sua função.

Nesse sentido, ao aliar tais discussões com o cerne dessa pesquisa, consideramos nuperimanente, por exemplo, que falar de/em/sobre escola inclusiva tem sido, praticamente, abordar e tratar de algum tipo de deficiência com laudo médico ou psiquiátrico, em um viés em que não faz sentido falar de inclusão social nos seus diferentes aspectos econômicos, étnico-racial ou de gênero. Tratar de outro tipo de inclusão que não seja da educação especial, é carregada de sentido ideológico considerado imoral nos tempos atuais. No caso brasileiro, temos a obra de Paulo Freire, que aborda de forma mais radical a exclusão/inclusão na escola, em sua luta contra a opressão a partir da educação, levou-o, hodiernamente, a ser considerado como um dos grandes responsáveis pelo suposto fracasso da educação formal no país. Sua obra inicial, que culmina com a Pedagogia do Oprimido (1969), constitui-se em uma pedagogia da libertação tratando-se de uma forma típica na/da América Latina, dentro de um movimento filosófico e teológico em que surge a "questão da libertação" (DUSSEL, 1995, p. 22). Nesse sentido, a Pedagogia da Libertação de Freire está introduzida no movimento pedagógico brasileiro em diálogo com a América Latina. $\mathrm{O}$

\footnotetext{
${ }^{3}$ Referimo-nos às reformas do Ensino Médio e às últimas versões da Base Nacional Comum Curricular. ${ }^{4}$ Dentre as quais podemos citar: Fundação Lemann; Instituto Unibanco; Fundação Itaú; Instituto Inspirare; Todos pela Educação; Instituto Natura; Instituto de Co-responsabilidade pela Educação (ICE). 
conceito de educação inclusiva, parece não comportar mais a luta contra a opressão no sentido mais amplo da inclusão, mas passa a se restringir a um certo tipo de sentido de educação especial. Com isso, emancipar o estudante é, de certo modo, um tipo de adaptação à sociedade através das competências e habilidades.

O texto se move na perspectiva de indagar se ainda faz sentido falar em educação libertadora, ou então,dito de forma mais vasta, pode a educação escolar ser considerada uma prática de liberdade na América Latina,levando-se em consideração um mundo globalizado? Assim sendo, faz sentido analisar a lógica de fundo que se estabelece contra o que está posto, no momento em que a história caminha em direção ao progresso e, nesse sentido, se um grupo social, uma instituição ou os sujeitos não acompanharem o desenvolvimento posto, isso significa que os casos omissos que não se adaptarem e acomodarem ao sistema devem ser tratados particularmente, sendo sempre considerados como problemas localizados que precisam ser combatidos ou adequados ao já estabelecido.

No caso de pessoas ou estudantes, isso seria (é) feito por meio de alguma terapia, algum coach (coaching) ou pela indicação de algum remédio, a fim de se "descobrir" qual o problema que o sujeito possui pelo fato de não conseguir se adequar/adaptar; no caso das instituições, as mudanças seriam (são) realizadas nas formas de gestão e administração, do mesmo modo que as economias de países periféricos precisam seguir as cartilhas dos países centrais. Desta forma, desenvolver melhor os objetivos, capacitar melhor os sujeitos, aprimorar as competências e habilidades passa a ser a função da educação escolar. Em suma, o sistema é (sempre) bom, os indivíduos que não são competentes o suficiente para se adequar às mudanças e situações exigidas pela globalização.

O discurso de questionar a globalização como um sistema mundial, pode ser considerado como um tanto ultrapassado, e somente faz sentido falar em libertação se há opressão. Se considerarmos a lógica posta como inadequada, então significa que necessitamos fazer uma mudança estrutural, ou ainda, transformações de situações que julgamos serem excludentes e aniquiladoras. Se não pretendermos somente legitimar o que está posto, mas abordar uma educação para além do que está posto, para além da adequação e mesmidade, exige o pensar em uma educação que transforme a realidade dada como naturalmente "justa" e "adequada". Contudo, essa transformação pode ser 
considerada como uma ameaça ao sistema vigente, podendo-se, inclusive, reagir de forma violenta para a manutenção do status quo.

Com isso, podemos aferir que o problema que aqui enfrentamos está diretamente ligado com a forma pela qual fazemos a educação escolar, ou seja, passamos a legitimar o sistema se considerarmos que as diferenças ou as limitações dos sujeitos (alunos) são somente "problemas subjetivos", isto é, do "próprio eu".

Nessa direção, a presente pesquisa se baseia na análise bibliográfica e na perspectiva hermenêutica de interpretação crítica da questão do outro na educação escolar. Acreditamos que somente faz sentido falar em uma pedagogia da libertação se há uma experiência de opressão ou, no mínimo, a necessidade de libertação, muito ofuscada atualmente pelo que denominamos de globalização. Assim sendo, indagamos no que consiste uma experiência inicial de libertação num mundo globalizado, pensado a partir da América Latina?

Em primeiro lugar, analisamos no que implica, historicamente, ser e pensar a partir América Latina - a inauguração do América como produto da modernidade européia -, e o surgimento da "questão da libertação". Por conseguinte, aborda-se o surgimento da questão da libertação e o aparecimento do Outro, a partir de Enrique Dussel, com o intuito de compreender as características da globalização e da sociedade hodierna, além de suas implicações para pensar o Outro diferente e igual. Por fim, diante do contexto brasileiro, tematiza-se, a partir de Paulo Freire, Enrique Dussel e alguns de autores contemporâneos, a dificuldade de se constituir pressupostos para pensar uma pedagogia da libertação em tempos atuais.

\section{O EFEITO DA MODERNIZAÇÃo PARA AMÉRICA LATINA E OS SEUS REFLEXOS PEDAGÓGICOS}

O triunfo das democracias liberais assentadas sobre um estado constitucional, com uma economia de mercado capitalista, em que os direitos estão formalmente assegurados. Contudo, recentemente, em decorrência do consumismo voraz e desenfreado, com as suas mais variadas faces e superfluidades tem forçado e solicitado para a manutenção do excludente sistema capitalista mesmo como endurecimento das liberdades individuais em função da liberdade econômica. Há, nesse sentido, uma 
hegemonia do capitalismo, que se impõe de modo inquestionável como a melhor opção histórica/social/econômica etc, especialmente após o fim da URSS em 1991. A democracia formal é, oficialmente, a nossa forma de legitimação do poder, que já é amplamente difundida nos limites da representatividade, em que a manipulação das sociedades de massa e os próprios mecanismos de validação são insuficientes para assegurar o protagonismo dos cidadãos em condições de igualdade (isonomia).

As sociedades democráticas liberais abandonadas à lógica do mercado abrem espaço para uma acentuada desigualdade social e de uma crise ecológica sem precedentes. Os direitos e deveres do cidadão garantem a igualdade formal, quase insignificante politicamente, uma vez que não conseguem se manter longe do nacionalismo com características excludentes e de fundamentalismos religiosos intolerantes. Este modelo de sociedade desenvolvido é reflexo dos processos da modernização. A questão ecológica, por exemplo, tem sido o grande ponto fraco da modernidade que se levanta e sustenta sob a égide do progresso, da exploração. Por mais que a sociedade se moderniza, em termos de sustentabilidade do planeta estamos em rumos inversos. Se falarmos em progresso como sinônimo de desenvolvimento, então não podemos adjetivar o progresso em termos de viabilidade de vida no planeta, e corremos um sério risco de torná-lo inabitável e, quiçá, supérfluo para as novas gerações. As questões ecológicas põem sob suspeita a modernização enquanto sinônimo de progresso.

Não obstante e de forma específica, os países latino-americanos nascem sob o processo de modernização européia, como colônias das sociedades tidas como "civilizadas e modernas". Assim sendo, "[...] a cultura ameríndia, porque difere da européia, é considerada como bárbara, desprezível, sem valor" (BOUFLEUER, 1991, p. 79). Além disso, constituem um processo de integração muito efêmero, “[...] ou melhor, apenas foi possível uma integração perversa sob o signo do espólio, exploração ou exclusão" (ZAMORA, 2008, p. 20). Este processo da história latino-americana permite um estranho ethos como forma de normalidade deste processo de marginalização mundial. Em síntese, é normal que a modernidade produza este processo de exclusão devido a cronologia histórica. Enigmaticamente, legitima-se o processo de exclusão como sendo constitutivo da própria constituição da América (exceção feita no norte do continente). A histórica linear e evolutiva coloca frente a frente sociedades 
"desenvolvidas" e "civilizadas"com sociedades "tradicionais" e "atrasadas". Sob esta lógica, temos como padrão de análise as sociedades modernas que apresentam e consideram numa escala de inferioridade as sociedades que não seguem este curso. $\mathrm{O}$ diferente, em termos de sociedade, é a civilização contra a barbárie, para Zamora (2008, p. 21), "considerar a barbárie como uma forma de vida do 'outro' como também vê-la como uma forma que se superou".

Conforme Baudrillard e Guillaume (2000, p. 113, tradução nossa):

\begin{abstract}
Já não trata de matá-lo, devorá-lo ou seduzi-lo, nem de enfrentá-lo ou rivalizar com ele, também não se trata de amá-lo ou odiá-lo; agora, trata-se primeiro de produzi-lo. O Outro deixou de ser um objeto de paixão para converter-se em um objeto de produção. Poderia ser que o Outro, em sua alteridade radical ou em sua singularidade irredutível, tenha se tornado perigoso ou insuportável e por isso necessário exorcizar sua sedução? Ou será simplesmente que a alteridade e a relação dual desaparecem progressivamente com o aumento potencial dos valores individuais e com a destruição de valores simbólicos?
\end{abstract}

Nesse sentido, a estratégia histórica é tipicamente do processo colonizador, que torna as formas internas da própria sociedade que se destoam da modernização, como forma de adequação. Comportamentos que não refletem os valores da sociedade moderna devem ser adequados ou aniquilados, de tal sorte que, enquanto nada puder ser feito de modo a tensionar esse movimento, se aceitará essa perspectiva como parte integrante e "natural" do processo. Os modos de vida diferentes podem até persistir no interior da sociedade, contanto, desde que não afetem a marcha para o progresso.

Todavia, quando estes grupos sociais se organizam para lutar pelos seus direitos para além do status quo, significa que estes devem ser combatidos com uma ideologia perversa e abafadora. Além disso, passam a ser considerados como resquícios de barbárie, para Sennett (1988, p. 325), tais evidências se aprofundam nas sociedades modernas onde "[...] forasteiros, desconhecidos, dessemelhantes, tornam-se criaturas a serem evitadas" e combatidas. Todo movimento que se pautar na luta por direitos contra a marcha do progresso deve ser descaracterizado, por isso, formas de vida diferentes das consideradas "ideais" ou "condizentes" deverão sempre ser combatidas:

Não será necessário grande esforço para reconhecer os múltiplos serviços prestados por esta estratégia. De um lado, serviu para tornar invisíveis formas 
de barbárie inerentes à Modernidade ou, inclusive, para identificar e estigmatizar grupos sociais dentro das sociedades industrializadas, objetos de processo de exclusão, exploração ou extermínio; e, de outro, permitiu legitimar a luta, em muitos casos exterminadora, contra formas definidas previamente como bárbaras, empregando meios e conduzindo para efeitos que ultrapassam em muito a barbárie atribuída aos supostos incivilizados. (ZAMORA, 2008, p. 21).

No tocante à educação escolar, esta estratégia que, de um lado, visa mostrar certos grupos sociais como inadequados e, de outro, combatê-los sistematicamente, tem se mostrada de alguma forma eficiente no sistema de ensino formal, tanto que passamos por um movimento nacional de combater qualquer tomada de posição que não seja adequada com a estrutura vigente, no viés de caminhar sob a perspectiva de desideologização da educação, abrindo, grosso modo, o leque para qualquer tipo de tema transversal que tome uma posição contrária ao desenvolvimento e formação humana. Chegamos ao extremo de questionar uma república, democracia e os direitos humanos que não estejam vinculados para o progresso da sociedade capitalista.

A América Latina, desde a sua fundação, é um produto da modernidade. A história é marcada por uma dizimação de muitos povos e culturas, povos que viviam neste território foram silenciados, em um movimento tipicamente caracterizado de genocídio, enquanto forma de assassinato praticado pelo estado ou autoridade contra um determinado grupo ou etnia que não se adequava às exigências da civilidade "boa". (ZAMORA, 2008). No caso dos americanos, estes se caracterizam por uma pseudoeuropeização, pois legam a língua e a cultura européia, agregando os elementos nativos e africanos mesmo que estes não sejam aceitos formalmente. A formação latinoamericana possui algum vínculo com o colonizador, uma boa educação é feita no velho continente, “[ [...] os jovens ameríndios devem deixar o seu 'mundo' para serem educados com a base nos fundamentos da cultura européia, conforme o sistema da Cristandade”. (BOUFLEUER, 1991, p. 79).

Dentro do contexto mundial, após 1929, surge um nacionalismo popular nos países latinos, que reflete no Brasil com o surgimento da Escola Nova, em que há um manifesto contra o domínio e exploração, outro movimento significativo foi o dos anos 60, especialmente quando a juventude se manifestou contra o consumismo multinacional, expresso pedagogicamente com o advento de reação ao capitalismo a partir dos movimentos reacionários, é neste período que surge a "questão da libertação", 
que se impõe como possibilidade outra de tensionar a globalização e a educação escolar. É esta questão que será abordada doravante.

\section{A POSSIBILIDADE DA EXPERIÊNCIA DE LIBERTAÇÃO EM ÉPOCAS DE GLOBALIZAÇÃO}

O surgimento de um movimento da libertação na América Latina, que se desenvolveu em várias frentes, envolvendo a filosofia, teologia e pedagogia, tinha como objetivo libertar o latino-americano de sua histórica de situação de opressão e adequação. Um pensamento que emerge a partir do Outro - enquanto completamente outro - um olhar do diferente que é o índio dizimando, o escravo coisificado, a mulher como objeto sexual, a criança menosprezada. A identidade de ser latino-americano passou a ser vista como um ser humano de segunda categoria, que pretendia também ser "[...] o porta-voz dos gritos por libertação de todos os povos oprimidos" (BOUFLEUER, 1991, p. 56). Dentre pensadores que abordam esta temática destacamos as contribuições de Enrique Dussel.

Enrique Dussel, ao retornar para Argentina em 1969, percebe uma situação em que o Outro é oprimido, para ele: "[...] a experiência inicial da Filosofia da Libertação consiste em descobrir o 'fato' opressivo da dominação, em que sujeitos se constituem 'senhores' e outros sujeitos [...]" (DUSSEL, 1995, p. 18). Este fenômeno do Outro enquanto oprimido é o que despertou a necessidade de se pensar em como libertar este Outro, que passa a ser uma libertação do pobre. Para Dussel, a capacidade de perceber o fato da opressão é o despertar de uma filosofia da libertação. Sem a capacidade de indignação frente a uma realidade que se apresenta como injusta, bárbara, inconveniente e desumana, não há como e nem motivos para se pensar em libertação. A filosofia da libertação, que parte do oprimido e da realidade desumana, é a única que não tem privilégio nenhum para defender, pois, segundo Dussel, “A inteligência filosófica nunca é tão verídica, límpida, tão precisa como quando parte da opressão, e não tem privilégio nenhum para defender, porque não tem nenhum" (DUSSEL, 1977, p. 10-11). Trata-se, portanto, de um movimento em oposição a modernidade européia que havia se instalada e instaurada no mundo: "Nós estávamos conscientes de que éramos 'a outra face' da Modernidade" (DUSSEL, 1995, p. 47). 
Em meados do século XX, a América Latina estava em pleno efeito do macarthismo, com o caso Cuba, todo movimento intelectual que defendesse o oprimido era ideologicamente, na Guerra Fria, considerado comunista, não foi diferente ocorreu como movimento libertador. Em períodos binários, tecer qualquer crítica a um certo sistema, insere o sujeito na condição de oposição, exatamente o que aconteceu (e continua acontecendo) com a questão da libertação do oprimido e com a necessidade de se compreender o tempo presente, isto é, fazer o movimento de compreensão e, geralmente, de crítica, enquadra o sujeito à oposição e não como alguém que pode, excepcionalmente, aperfeiçoar as relações humanas.

A partir desse contexto, indagamos sobre o que constitui fazer uma experiência inicial contra a opressão e as condições desumanas/injustas? De onde emerge essa questão da libertação? Afirmamos, previamente, que ambas as questões aparecem na perspectiva hermenêutica da experiência dusseliana. A experiência inicial, que aqui assumimos, deve produzir efeitos de provocar, no sujeito, alterações e transformações. Para alcançar este desígnio nos aproximaremos da palavra experiência, que deve resistir à definição ou conceituação da experiência, e simplesmente fazer soar a palavra experiência, para que “possa causar certo 'desassossego', e disso dizer mais outra coisa, para além do que diz, uma causa, uma abertura para o real'(LARROSA, 2016, p. 43). Uma experiência, que segundo Larrosa, deve fugir aos padrões de experiência, causar desassossego, fugir da normalidade.

\footnotetext{
Neste marco, tenho a impressão de que a palavras experiência ou, melhor ainda, o par experiência/sentido, permita pensar a educação a partir de outro ponto de vista, de outras maneira. Nem melhor, nem pior, de outra maneira. Talvez chamando a atenção sobre aspectos que outras palavras não permitem pensar, não permitem dizer, não permitem ver. Talvez configurando outras gramáticas e outros esquemas de pensamento. Talvez produzindo outros efeitos de verdade e outros efeitos de sentido (LARROSA, 2016, p. 38).
}

Manter a experiência num nível de estranhamento provoca a abertura, a emersão de uma nova perspectiva de realidade, que tem um efeito inovador no sujeito em formação. Em todos os casos, iremos nos deter a este aspecto formativo da experiência, principalmente no modo de o estudante se constituir a partir de sua experiência. Para Larrosa, quase nenhuma experiência nos acontece, há uma "destruição da experiência", quase ninguém faz experiência, ninguém se aventura a algo novo, falamos de lugares, de instituições e de discursos padronizados, não se 
"ex-põe": "É incapaz de experiência aquele a quem nada lhe passa, a quem nada the acontece, a quem nada lhe sucede, a quem nada o toca, nada the chega, nada o afeta, a quem nada o ameaça, a quem nada ocorre" (LARROSA, 2016, p. 26). Por isso, para Larrosa (2009, p. 14, tradução nossa), “[...] a experiência é 'isso que me passa'. Não aquilo que passa, mas 'isso que me passa"”.

Nessa direção, a experiência tem a ver, etimologicamente, com um "caminho perigoso", caminho que nos tira do lugar e nos expõe. Exatamente o que para Dussel tem a ver com a experiência inicial, isto é, envolve o Outro tratado como completamente Outro, como pobre, e que é uma experiência inicial de todo o latino-americano. Este pobre é o oprimido: "O oprimido, o torturado, o que vê ser destruída a sua carne sofredora", que não consegue simplesmente manifestar a sua opressão, através de uma luta consciente para a libertação, "eles simplesmente gritam" (DUSSEL, 1995, p. 19). Muitas destas situações estão completamente aniquiladas na história "sem deixar rastro e nem eco delas" (ZAMORA, 2008, p. 22).

Esta experiência inicial, o thaumazein da filosofia da libertação é a capacidade da experiência do Outro, do pobre, do excluído, da mulher, do índio, do escravo e de tantos outros:

\begin{abstract}
A origem radical de tudo não é, aqui, afirmação de si (do eu próprio); para isso é preciso poder refletir, aceitar-se como valor, descobrir-se como pessoa. Achamo-nos bem antes de tudo isso. Estamos na presença do escravo que nasceu escravo e que nem sabe que é uma pessoa. Ele simplesmente grita. O grito - enquanto ruído, rugido, clamor, protopalavra ainda não articulada, interpretada de acordo com seu sentido apenas por quem 'tem ouvidos para ouvir' - indica simplesmente que alguém está sofrendo e que no íntimo de sua dor nos lança um grito, um pranto, uma súplica (DUSSEL, 1995, p. 19).
\end{abstract}

A presença do Outro, que não se entende, que não reflete sobre a sua situação, mas que, constantemente sofre, precisa receber a origem radical da experiência que assombra, que exige do sujeito uma mudança de postura, que faz emergir a consciência ética, consciência que está aliada ao compromisso da e com a libertação. É um grito que precisa ecoar de forma responsável. A possibilidade de ter ouvidos para ouvir, necessita do sujeito uma possibilidade de fazer a experiência intencionalmente, uma abertura ao Outro, um deixar se afetar pelo Outro. Esta sensibilidade pelo Outro exige consciência ética, que acolhe o sofrimento do Outro e responde com responsabilidade ao Outro. $\mathrm{O}$ "ouvinte responsável" surge quando na experiência "tiver sentido o impacto da súplica do Outro". (DUSSEL, 1995, p. 19). O grito do Outro sentido como súplica é anterior à 
reflexão. A experiência originária da filosofia da libertação está no Outro pobre que comove. O Outro é anterior a constituição do eu.

Num mundo de economia de mercado globalizado, o Outro é o pobre, o que "tem fome", aquele que precisa, antes de tudo, ser alimentado. Porém, todos os grupos de "outros" que impedem o curso da história do progresso e do desenvolvimento acabam por serem alvo de aniquilação. Em primeiro plano, é preciso reconfigurar a nossa situação de latino-americanos no processo de modernização, que se configura no processo de globalização. A globalização tem algumas características pertinentes no que significa pensar o Outro e se comprometer como este Outro, principalmente porque o processo mundial é a globalização que substitui a ideia de imperialismo, o tradicional conceito de dependência parece ocultar-se dentro de uma nova configuração e, em vez dele se tornar incapaz de expressar a relação na globalização, ele se torna um conceito onipotente. Perde o sentido, por isso, falar em exploração, opressão, classe social, burguesia ou colonialismo frente a neutralidade do mundo globalizado. Para Rosenmann, “[...] o conceito de globalização pressupõe uma realidade neutra, uma fase ou estágio da evolução da ordem mundial na qual estão imersos de igual forma países dominantes e países dependentes" (ROSENMANN, 2008, p. 131, tradução nossa).

A “globalização expressa uma nova realidade", que segundo Rosenmann (2008), é um conceito neutro de valores, mas que encobre uma certa ideologia. Este processo de "desideologização" ou "despolitização" do processo de globalização faz normalizar o processo de concentração e centralização do capital em escala transnacional. Não obstante, tem como ponto forte o progresso científico induzido e expandido pela revolução tecnológica, a incorporação de técnicas despolitizadas no processo de produção.

\footnotetext{
Sob esta visão tecnocrática, se aduz a necessidade de acelerar as mudanças de maneira que favoreçam uma eficiente inserção global e evita o atraso que fazia perder a oportunidade para localizar estrategicamente em um grupo de países capazes de subir ao trem do progresso, manifestado na robótica, na informática, na inteligência artificial, na transformação do mercado de trabalho, na produção e no capital (ROSENMANN, 2008, p. 132, tradução nossa)
}

A marcha do progresso parece que torna impossível se opor a este fenômeno espontâneo da globalização, em que países periféricos possam se tornar países 
desenvolvidos, o que se impõe é que basta participar e seguir as normas do progresso. As políticas governamentais de educação se justificam na perspectiva de inserção aos modelos de desenvolvimento, ou seja, "[...] se queres estar entre os melhores, basta modificar e aceitar os critérios que impõe a globalização" (ROSENMANN, 2008, p. 132, tradução nossa). Segundo Rosenmann, a ideologia da globalização neutra esbarra numa adesão radical, e assim, "qualquer crítica tendente a mostrar défices não contemplados na globalização é rejeitada em prol de um mundo feliz" (ROSENMANN, 2008, p. 134, tradução nossa).

Nessa direção, quem é o Outro no mundo globalizado e tão competitivo? Quem é o Outro que permite fazer uma experiência inicial da libertação? Quem é o Outro que exige de mim e do Outro um olhar, um ouvido responsável, que afeta aminha própria felicidade? Quem é o Outro, estudante e jovem na América Latina? E qual é a experiência inicial que não comprometa a satisfação de um "mundo feliz"? Estas e outras questões pretendem dar luz à experiência inicial de libertação a partir do Outro, que exigem de mim e, também, do Outro, uma comoção que afeta e compromete a presença do Outro como mínimo de consciência ética possível para uma vida coletiva, na busca de vivermos juntos. Trata-se da possibilidade da alteridade, de um Outro permanente (BAUMAN, 1996), um Outro que não é apagado e excluído, pois, “o desaparecimento da alteridade significa que vivemos numa época pobre de negatividades" (HAN, 2017, p. 14).

A desideologização e despolitização são os primeiros efeitos de que o Outro não é mais um compromisso político e social necessário e exigente, mas somente na medida em que faz parte de meu mundo. Angariado pela despersonificação do Outro e pelos meios de comunicação, o Outro passou a ser uma conta virtual, um perfil, uma curtida, um like, uma selfie, há alguns Outros que comovem quando este Outro entra em meu mundo, por alguma relação casual ou de interesse, mas que tende, devido a mobilidade da vida, a desaparecer nos excessos de informação, nas demandas do cotidiano, nos não likes recebidos.

A tecnocracia exige uma gama protocolar muito grande, uma gama de sujeitos que precisam cumprir tarefas para se adaptar às condições da economia de mercado. Há alguns outros que aparecem vezes ou outras, em relações afetivas, em relações de trabalho, como clientes, como terapeutas, como professores, mas normalmente não 
permitem o comprometimento constitutivo. Num mundo globalizado, de informações em massa, temos poucas experiências significativas, e em alguns momentos temos lampejos de libertação, de comprometimento com o Outro. O Outro pelo qual nos comprometemos é o Outro que compartilha de algum interesse em comum, de algum objetivo compartilhado.

A ausência de uma pólis faz com que não haja mais compromisso em comum em um mundo globalizado, é cada um para si e por si. A ausência de uma consciência ética geral impede de me comprometer com a causa do Outro, enquanto infinitamente Outro. Trata-se da ausência e inexistência de uma ética da responsabilidade, como nos lembra Hans Jonas (2006). A experiência de libertação é uma experiência dolorida, que na maioria das vezes ameaça o "mundo feliz", a positividade, ou na melhor das hipóteses, ameaça uma vida feliz reduzida ao "eu" e não ao "nós".

Experienciar os movimentos sociais, a questão ecológica, os direitos humanos e dos animais dentro de um mundo globalizado, exploratório e competitivo, que tem um efeito devastador sobre o sujeito, e acaba se recolhendo e retraindo no seu mundo para tornar a sua experiência inicial libertadora possível. A fragilidade e dramaticidade da condição humana em um mundo globalizado se atenua, e caso não haja um exercício constante e formativo de acordo com suas limitações, faz jogar a criança fora com a água do banho. A questão que se coloca é saber se o professor consegue fazer esta ou alguma experiência pedagógica de libertação na prática educativa contemporânea.

\section{A PEDAGOGIA DA LIBERTAÇÃO EM TEMPOS DE GLOBALIZAÇÃO}

A experiência inicial da libertação ocorre em Paulo Freire, especialmente, em sua sui generis experiência enquanto advogado, em que não conseguira executar uma dívida de um jovem dentista, fato retratado na obra Pedagogia da Esperança: Um reencontro com a Pedagogia do Oprimido (1992), que vem acompanhada pela convivência com os oprimidos: "seus corpos de oprimidos, hospedeiros, sem ter sido consultados, dos opressores" (FREIRE, 1992, p. 19).

Essa sensibilidade de compreender o Outro - o completamente Outro -, faz com que Dussel nos aconselhe de ter a experiência inicial de libertação, na educação escolar isso se traduz no diálogo com o oprimido. Segundo Freire, não se trata mais de falar 
sobre, mas "com participantes" (FREIRE, 1992, p. 24), esta aproximação da linguagem do Outro é o esforço do educador, o papel de contribuir na emancipação do oprimido, que epistemologicamente exige uma mudança radical: "eu ainda quase sempre partia de meu mundo, sem explicação, como se ele devesse ser o 'sul' que os orientasse" (FREIRE, 1992, p. 24).

O esforço de compreender o mundo do Outro é o problema nuclear da educação escolar enquanto prática da libertação, e quase continuamente muito sofrido para o educador, uma vez que exige a transformação de compreender o mundo do outro, para a partir dele propor a libertação com a leitura de mundo do educador (FREIRE, 1992). Este esforço epistemológico de compreender o mundo do outro é também uma ruptura existencial que requer uma libertação mútua do educador e educando. A capacidade do educador de se colocar no mundo do outro, partir do mundo do outro numa linguagem do Outro é o grande desafio pedagógico da libertação: “Trata-se de uma revolução copernicana em pedagogia, que ainda está longe de ser compreendida" (DUSSEL, 2000, p. 436).

Nossa indagação inicial chega agora a vias de fato, uma vez que a experiência inicial da filosofia da libertação se encontra afetada pela globalização, que possui neutralidade ideológica, mediada pela tecnologia de informação e uma tecnocracia, que torna os gerenciamentos institucionais mediados pela tecnologia, fazendo aparecer as marchas do desenvolvimento e do progresso. Não temos mais uma contraposição política depois da queda do muro de Berlim, sendo assim, não faz sentido em opor o capitalismo por uma via socialista ou crítica ao capitalismo.

\footnotetext{
Tomando todos estes aspectos em consideração, achamos, todavia, que problemas aparentemente anacrônicos, 'fora da moda', 'superados' para a Europa, Estados Unidos ou Japão, não o são tanto para as vítimas no mundo periférico, na África, Ásia, América Latina ou na Europa do Leste; para os homeless[sem-teto], marginalizados e empobrecidos dos países centrais; para ecologistas e feministas (DUSSEL, 2000, p. 501).
}

\footnotetext{
${ }^{5}$ Importa dizer que essa incompreensão é muito atual, presente, inclusive, nos discursos do Presidente Jair Messias Bolsonaro, este considera a perspectiva de compreender o mundo do Outro e mostrar ao aluno como "o mundo é", que no fundo, se trataria de uma ideologização e politização do outro por parte do professor, que é considerado como doutrinador. 
Assim sendo, parece não fazer mais sentido, na educação escolar, falar em pedagogia da libertação no seu sentido de alteridade, humanidade e mundanidade, conforme proposto por Dussel e Freire. Em um país que se caracteriza pela desideologização/despolitização, nada mais "natural" do que tratar da escola como um espaço neutro politicamente, de uma educação que seja baseada em tecnologias de informação e das inúmeras maneiras de "inovação" e "renovação" e, conseqüentemente, que desenvolva certas competências e habilidades nos educandos. Tudo na perspectiva da funcionalidade, mas jamais levando-se em consideração uma reflexão de cunho filosófico. Nessa direção, como poderíamos definir uma experiência pedagógica de libertação nesses tempos de globalização, competitividade e exclusão a partir da América Latina?

A primeira hipótese é conseguir, epistemologicamente, compreender a globalização como um projeto inacabado da Modernidade, retornando aos temas "fora de moda", e retornar a temas como os de emancipação, a partir da compreensão do Outro, inspirados na negatividade, na alteridade, no sofrimento e na experiência inicial. Em termos de escola, deve-se retornar aos temas de opressão, exclusão, injustiça, barbárie e adequação, no intuito de se resgatar a compreensão de colonizados/colonização, em síntese, trata-se de apresentar o legado histórico e culturalmente produzido pela humanidade, a fim de que Auschwitz não se repita. Além disso, esse argumento nostálgico, também retorna pelas vias ecológicas e também na e pela educação ambiental, que urge sempre com a politização e parece ser condizente com uma afronta ao desenvolvimento, ao progresso e a uma vida supostamente feliz, resultando e causando, por isso, algum tipo de sofrimento voluntário.

A segunda alternativa é manter em suspensão o discurso totalizante, o sentido ético último da educação, e aderir a tese do fazer o que dá para fazer. De uma forma mais circunscrita, significa não tentar transformar o sistema educacional como um todo, mas fazer pequenos ajustes a partir do que já está posto. Esse tipo de ação não compromete o sujeito como um todo, mas apenas em uma determinada região da realidade, que representa uma visão pós-moderna e, infelizmente, aceita em nossas contradições atuais.

A globalização, a dificuldade do discurso totalizante e o desenvolvimento tecnológico com vistas ao progresso e à satisfação de necessidade imediatas (reais ou 
inventadas), impediram o movimento de uma experiência inicial da libertação, do mesmo modo na educação escolar, a necessidade de adaptar a carga horária às condições de trabalho, a exigência curricular, mesclada com a necessidade de adaptação tecnológica ${ }^{6}$ por parte do educador, parece ocultar nas demandas diárias a possibilidade do aparecimento do Outro na sala de aula. O Outro, o analfabeto, o excluído socialmente/historicamente, é somente mais um, no movimento voraz e supérfluo do progresso e das exigências do capital.

"Sempre teremos que ter pessoas para limpar o chão" dizem os educadores, "a escola não me ajuda na minha tarefa de empacotador" diz o educando, a escola deveria "preparar para o trabalho, meu filho deveria sair com uma profissão" diz um pai. E assim, o cenário pedagógico impede de fazer qualquer experiência inicial de libertação, reduzindo a explicação do mesmo, a mesmidade. O Outro enquanto pobre, encontra no professor um sujeito similar que não consegue superar as demandas de seu dia, o professor deixa de ser educador e passa a gerenciar aulas, passa conteúdo sem significado e sentido algum, muitas vezes, inclusive, a disciplina e/ou conteúdo não fazem nem sentido para o próprio professor, que dirá para o aluno.

Para Rosset (1993, p. 66),

Se a escola é feita para ensinar, então é necessário que ela ensine alguma coisa [...]. A pedagogia acabou por suplantar a própria instrução. Temos hoje docentes que não sabem nada, mas possuem uma misteriosa ciência da educação, verdadeira mitologia dos tempos modernos. Resultado: desde há uma dezena de anos vemos chegar ao ensino superior estudantes analfabetos.

É fundamental, portanto, que o professor tenha motivos que justifiquem o porquê de sua disciplina estar presente no currículo escolar, e o que pode, a partir dela, ser significativo para o pensamento e a vida dos estudantes, indiferente de seus antecedentes. Se isso não estiver claro para o professor, é melhor que arrume outra ocupação.

\footnotetext{
${ }^{6}$ Referimo-nos aos discursos contemporâneos que exigem do professor a utilização dos mais diferentes recursos tecnológicos, a fim de tornar as aulas mais "atrativas" e "prazerosas". Contudo, trata-se de uma exigência que ignora os pressupostos de formação integral do sujeito, ignorando, muitas vezes, aquilo que pode vir a fazer diferença na vida dos alunos, a saber, o conhecimento. Em síntese, o foco está nos métodos de aprendizagem e não naquilo que deveria ser ensinado às novas gerações, não raras vezes o professor está apenas a um passo na frente de seus alunos no que se refere ao conhecimento da disciplina. 
Encontramo-nos, nesse sentido, no mais profundo âmago da educação bancária, depositários não somente de conteúdo, mas de um treinamento avançado de competências e habilidades, sempre com o intuito de facilitar o processo, de torná-lo mais prazeroso e flexível, na contramão da exigência, do esforço, da determinação, do estudo demorado etc, justamente o que é a especificidade da instituição escolar. Por isso mesmo, trata-se de uma educação que encobre o Outro e a sua alteridade, que o reconhece como o mesmo, na sua mesmidade. Nessa direção, a pergunta de Skliar (2003, p. 29): “E se o outro não estivesse aí?”, faz todo sentido para o processo educativo, pois sem o outro não seríamos nada, nem precisaríamos de escolas.

Se o outro não estivesse aí, só ficaria a vacuidade e a opacidade de nós mesmos, a nossa pura miséria, a própria selvageria que nem ao menos é exótica. Porque o outro já não está aí, senão aqui e em todas as partes; inclusive onde nossa pétrea mesmidade não alcança ver (SKLIAR, 2003, p. 29).

Não obstante, as reformas, inovações e mudanças que se impõem à educação, principalmente no contexto brasileiro, parecem ignorar que há um outro aí, um outro que necessita de uma educação de qualidade, de professores de qualidade, de estruturas de qualidades, de condições iguais, enfim, de uma educação que esteja atenta ao Outro, atenta à experiência da educação de criar e recriar os conceitos e as próprias relações humanas, na abertura responsável, plural, ética, respeitosa e digna.

Para Schütz e Moura (2017, p. 50),

[...] as mudanças educativas nos pensam agora como uma reforma do mesmo, como uma reforma para nós mesmos. Elas nos olham agora como esse rosto que vai despedaçando-se de tanta maquiagem sobre maquiagem. As mudanças têm sido, então, a burocratização do Outro, sua inclusão curricular, seu dia no calendário, seu folclore, seu exotismo.

Necessitamos de uma educação que escuta o chamado do Outro e se preocupa em constituir e construir um mundo humano comum. Que possamos lembrar da tarefa educativa: cuidar de um mundo que não dispensa e nem exclui o(s) Outro(s), mas que depende dele(s), motivo este que leva à afirmação de que este mundo é, eminentemente, Humano! 


\section{CONSIDERAÇÕES FINAIS}

Inicialmente esbarramos com o problema histórico da América Latina e a impetuosidade do discurso da modernização e os efeitos constitutivos do mundo eurocêntrico. $\mathrm{O}$ efeito colonizador nas consciências, no pensamento, na língua e na religião dos povos, e um multifacetado e anacrônico espaço de exclusão e opressão, que em muitos casos constituiu-se e se constitui em genocídios étnicos e genocídios, e agora em aniquilação de muitas formas de vidas diversas.

Num segundo momento, dialogamos com a experiência inicial da filosofia da libertação, que causa o insight do Outro enquanto Outro pobre latino-americano, a partir das teorizações de Enrique Dussel. O que na década de setenta parece um discurso libertador semelha ter perdido seu viés ideológico, pois a globalização acaba por sugar o discurso da modernidade, configurando-o que parece não ter sentido falar em oprimido, em excluído, em colonizador e educação bancária, pois a globalização afeta todos os países e povos do mundo. Esta aparente neutralidade da globalização tem afetado o sistema de ensino formal, principalmente, em movimentos no Brasil, como: Escola sem Partido e Reforma do Ensino Médio, em que as competências e habilidades devem adequar o sujeito às exigências do mercado de trabalho, ignorando aquilo que compreende ser uma formação integral, e passando a consolidar os processos educativos à lógica do capital e a atuação dinâmica do mercado, já que um sujeito com visão reduzida e parcial, é mais fácil de ser manipulado, explorado e, inclusive, excluído.

Ademais, pela tecnologia temos ampliado o nosso mundo, temos acesso as mais diversas informações, basta um clique. Aquilo que parece nos impor uma lógica inexorável, que parece ir contra este desenvolvimento consiste em ir contra o mundo feliz e momentâneo. Porém, o calcanhar de Aquiles das questões ambientais volta e meia afere as nossas vidas, mas que devido a fluidez das experiências, passa despercebido assim como as inúmeras pseudo-experiências iniciais de libertação, - do tipo passa para a próxima.

O professor, dentro desta lógica global, desideologizante, tecnocrática e mercantil, também não faz a experiência pedagógica da libertação, muitos diários, muitos alunos, muitas horas, muito e pouco tempo, tudo isso, não está condizente coma experiência do Outro. A inclusão é vista como privilégio de poucos e restrita a 
problemas físicos, e no mar de estudantes, muitos são os excluídos, se não o são na escola serão no mercado de trabalho. E nesta lógica perversa, solidificamos discursos fortes, e numa autopiedade não há espaço para o Outro enquanto Outro, somente para um eu que necessita do Outro, para se reafirma como eu, infelizmente! Finalmente, gostaríamos de ressaltar que o objetivo de abordar a educação escolar e a presença do Outro, permanece ainda um caminho aberto a ser percorrido, por mim, você, nós, o Outro e tantos outros.

\section{BIBLIOGRAFIA}

BAUDRILlARD, J.; GUILLAUME, M. Figuras de la alteridad. México: Taurus, 2000.

BAUMAN, Z. Modernidad y Ambivalencia. In: BERIAIN, J. (Comp.) Las consecuencias perversas de la modernidad. Barcelona: Anthropos, 1996.

DAMKE, I. R. O processo de conhecimento na Pedagogia da Libertação: ideias de Freire, Fiori e Dussel. Petropólis: Vozes, 1995.

DUSSEL, E. Ética da libertação na idade da globalizaçao e da exclusão. Tradução de Ephraim Ferreira Alves; Jaime Clasen e Lúcia Orth. Rio de Janeiro: Vozes, 1998.

Ética de la Libertación: En la edad de la globalización e de la exclusión. Madrid: Simancas Ediciones S.A, 1998.

Ética da libertação: na idade da globalização e exclusão. Tradução de Ephraim Ferreira Alves; Jaime Clasen e Lúcia Orth. Petrópolis: Vozes, 2000.

FREIRE, P. Educação como prática da liberdade. Rio de Janeiro: Paz e Terra, 1967.

Pedagogia da esperança: um reecontro com a pedagogia do oprimido. São Paulo: Paz e Terra, 1992.

Pedagogia da autonomia. 22. ed. São Paulo: Paz e Terra, 2002.

Pedagogia do oprimido. 62. ed. Rio de Janeiro: Paz e Terra, 2016.

JONAS, Hans. O princípio responsabilidade: ensaio de uma ética para a civilização tecnológica. Tradução Marijane Lisboa, Luiz Barros Montez. Rio de Janeiro: Contraponto, 2006. 
LARROSA, J. Tremores: escritos sobre a experiência. Tradução de Cristina Antunes e João Wanderley Geraldi. 1. ed. Belo Horizonte: Autêntica, (Coleção Educação: Experiência e Sentido), 2016.

LARROSA, J. Experiencia y alteridad em educación. In: SKLIAR, C.; LARROSA, J. Experiencia y alteridad em educación. 1. ed. Rosario: Homo Sapiens Ediciones, (Pensar la Educación), 2009.

SKLIAR, C. Pedagogia (improvável) da diferença: e se o outro não estivesse aí? Tradução de Giane Lessa. Rio de Janeiro: DP\&A, 2003.

ROSENMANN, M. R. Pensar américa latina: el desarrolo de la sociología latinoamericana. Buenos Aires: Consejo Latinoamericano de Ciencias Sociales CLASCO, 2008.

ROSSET, C. A ciência da educação, mitologia dos tempos modernos. In: KECHIKIAN, A. Os filósofos e a educação (entrevistas). Lisboa: Edições Colibri,1993.

SENNETT, R. O declínio do homem público: as tiranias da intimidade. São Paulo:Companhia das Letras, 1988.

SCHÜTZ, J. A.; MOURA, L. R. de. A experiência escolar com o outro na alteridade. Revista Igarapé, Porto Velho (RO), V. 5, N. 1, p. 46 - 60, 2017.

ZAMORA, J. A. Theodor Adorno: pensar contra a barbárie. Tradução de Antonio Sidekum. São Leopoldo: Nova Harmonia, 2008. 